\title{
Enhancement of flavonols water solubility by cyclodextrin inclusion complex formation - case study
}

\author{
Marcin Lukasiewicz, Stanislaw Kowalski \\ University of Agriculture in Krakow, Department of Food Technology, \\ ul. Balicka 122, 30-149 Krakow, Poland \\ e-mail: rrlukasi@cyf-kr.edu.pl; phone: +48126624770
}

\begin{abstract}
:
The phenomenon of solubility increasing of nonpolar flavonol antioxidant - quercetin (QC) in water solutions containing $\beta$-cyclodextrin (CD) was studied. Complexation of $\mathrm{QC}$ by $\mathrm{CD}$ was investigated using phase solubility study. It allows to estimate the apparent formation constant for 1:1 host-guest complex. Additionally thermodynamic properties were evaluated as well showing spontaneous exothermic process of complex formation. Two solubility models were also employing to verify their applicability to predict QC concentration in solution. Those models included modified Apelbalt and Buchowski-Ksiazczak equations. In order to investigate the antioxidant properties of ternary systems $\mathrm{QC} / \mathrm{CD} /$ water a radical scavenging activity using stable radical of DPPH was performed. Experiments indicated that antioxidant activity is temperature and $\mathrm{CD}$ concentration-dependent. It was shown that complexation may inhibit the radical scavenging by QC or changing the scavenging stoichiometry.
\end{abstract}

\section{Keywords:}

cyclodextrin, inclusion complexes, thermodynamics, solubility modeling

\section{Introduction:}

Flavonols are a group of flavonoids that are built from the 3-hydroxy-2-phenylchromen-4-one. In the group the several compounds may be found. They differ from each other by means of phenolic $-\mathrm{OH}$ groups position ${ }^{1}$. Flavonols may be found in many fruits and vegetables. As a group of food constituent flavonols show a wide range of biological activity. Thus, the beneficial effects of diets rich in fruits and vegetables on human health are well documented ${ }^{1-3}$. Flavonols 
are commercialized as dietary supplements either as pure compounds (e.g. quercetin), extracts or mixtures.<smiles>O=c1c(O)c(-c2ccccc2)oc2ccccc12</smiles>

3-hydroxy-2-phenyl-4H-chromen-4-one<smiles>O=c1c(O)c(-c2ccc(O)c(O)c2)oc2cc(O)cc(O)c12</smiles>

2-(3,4-dihydroxyphenyl)-3,5,7-trihy droxy-4H-chromen-4-one

Figure 1. Molecular structure of flovonols (left) and quercetin (right)

Quercetin is a most common in flavonols group. Quercetin and its sugar-bound, or glycosylated, forms represent $60-75 \%$ of flavonoid intake ${ }^{4}$. Quercetin is known to have the ability for the oxidation of low-density lipoproteins prevention by means of free radicals scavenging as well as transition metal chelating. According to that, quercetin could help in the diseases prevention including cancer, atherosclerosis, etc. ${ }^{5}$. In plants, as most of flavonols quercetin is bound to sugars molecules forming O-glycosides. The most common quercetin glycosides have a sugar group at the 3-position such as quercetin-3-O- $\beta$-glycoside. According to that quercetin is poorly absorbed in human body because no enzyme is known to split the glycosidic bond. Aglycones, sugar-free flavonoids can easily pass through the gut wall, but flavonoids are rarely found as aglycones in plants ${ }^{6}$.

According to that the inclusion complexes of flavonols including quercetin with cyclodextrin may increase the bioavailability of this important compound. In literature several reports can be found on quercetin/cyclodextrin complexes synthesis. There is however only a few information on complexation thermodynamics. The presented paper focuses on finding the complexation constant as well as basic thermodynamic parameters. Solubility models are also applied to explain the quercetin transfer between solid state and water solution.

\section{Experimental:}

All the studies were carried out using food grade $\beta$ - cyclodextrin - Roquette (France) . Other reagents used : Quercetin - Sigma -Aldrich ( Poland ) ; 2,2-diphenyl-1-picrylhydrazyl (DPPH) Sigma-Aldrich (Poland), methanol- POCh (Poland), ethanol 96 \% POCh (Poland), acetonitrile POCh (Poland) had purity levels of p.p.a. and were used without further purification.

The analysis of quercetin was performed by liquid chromatography (HPLC) in the following condition: eluent, a mixture of $\mathrm{MeOH}: \mathrm{H}_{2} \mathrm{O}: \mathrm{CH}_{3} \mathrm{COOH}-43: 52: 5 \%$ (v/v), flow rate $1 \mathrm{ml} / \mathrm{min}$, 
$20 \mu \mathrm{l}$ sample volume. The measuring system consisted of a pump, UV-VIS detector and a column thermostat $\left(40^{\circ} \mathrm{C}\right)$. Column was used for the determination of working in RP mode: 18LiChristoper 100-05 (Knauer Germany). Quercetin analysis was performed at a wavelength of $360 \mathrm{~nm}$. The quantitative analysis was based on a calibration curve.

Dissolution studies were carried out in a temperature range of $30-60^{\circ} \mathrm{C}$ for the solutions of $\beta$ $\mathrm{CD}$ at concentrations of $0 \mathrm{mM}$ to $15 \mathrm{mM}$. In the vials for $7 \mathrm{ml} \mathrm{QC}$ was weighed (QC molar ratio: CD 5:1) and vials were filled with $5 \mathrm{ml}$ of $\mathrm{CD}$ solutions. The suspension was kept at constant temperature until equilibrium is reached. Changes in the concentration of the $\mathrm{QC}$ in the aqueous phase were monitored using HPLC. After the equilibration samples were filtered on a syringe filter with a diameter of pores 0.2 microns, and subjected to chromatographic analysis. The results obtained were used to calculate complexation dynamics, QC solubility as well as to estimate the equilibrium constant and the thermodynamic parameters of complexation.

\section{Results and discussion:}

As a result of investigation the basic knowledge on inclusion complex formation between quercetin and $\beta$-cyclodextrin has been obtained. Complexation of quercetin is a multistage process that includes: quercetin transfer from the solid state to the aqueous phase and introducing the molecule into the internal cavity of cyclodextrin. The overall scheme of the process is presented on Figure 2.

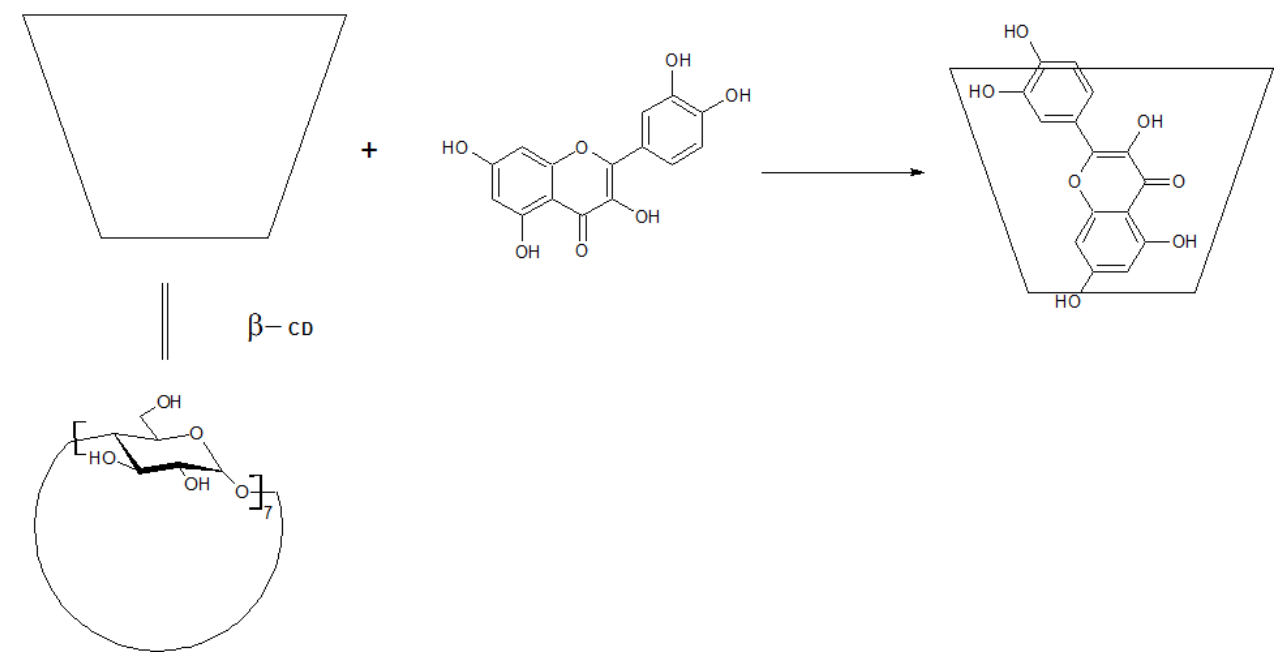

Figure 2. Complexation of quercetin by cyclodextrin

As designed in experiment the process takes several hours. In fact at the temperature range 30 to $60^{\circ} \mathrm{C}$ the rate of complexation varies as shown on Figure 3. In most cases the rate of complexation changes during the reaction progress. The rate of complexation drops in all investigated system and reaches near zero value at $90\left(60^{\circ} \mathrm{C}\right)$ and $150\left(30^{\circ} \mathrm{C}\right)$ hours of experiment. 
After that time the equilibrium is reached and the concentration of complex in a solution does not change in time. Additionally it was found the increase in cyclodextrin concentration in the system results in higher concentration of quercetin (after the equilibrium is reached). The phenomenon is temperature independent however the final value of quercetin concentration is a function of temperature.
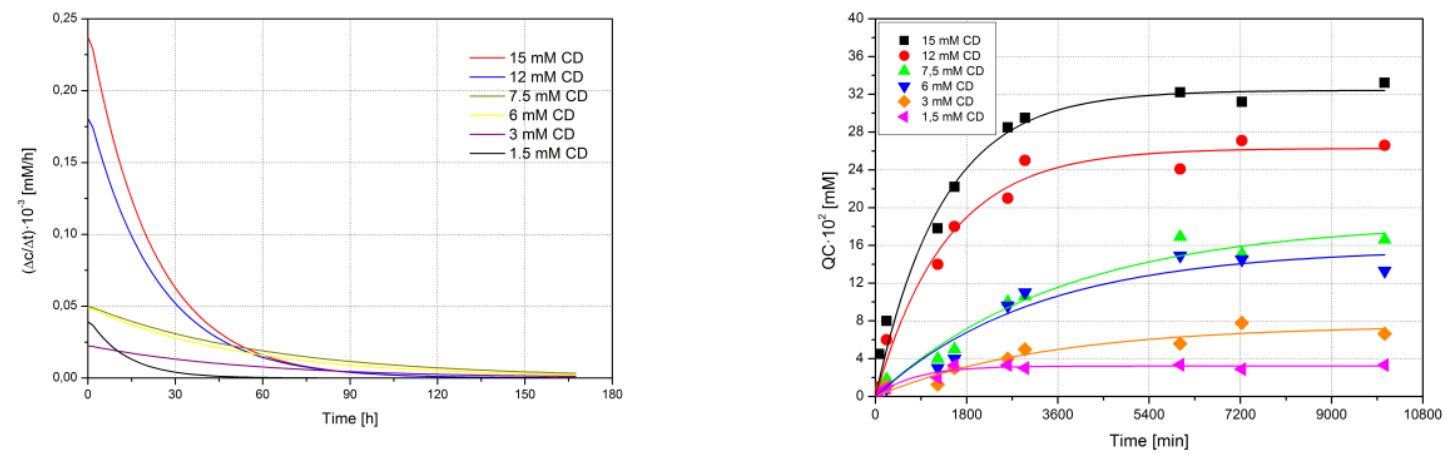

(A)
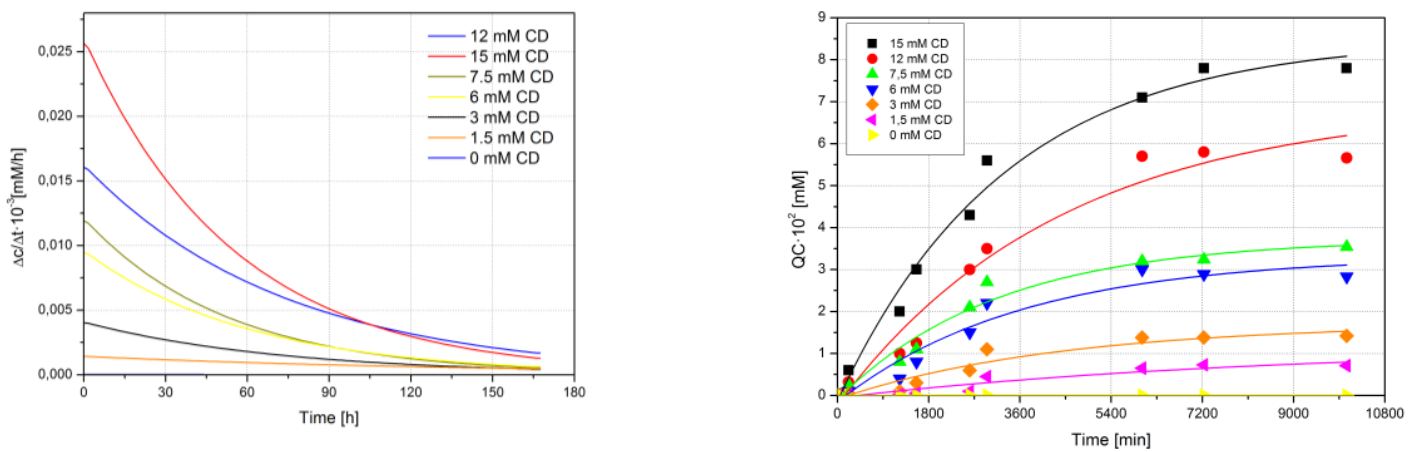

(B)

Figure 3. Complexation rate (left) and quercetin concentration (right) in solution at $60^{\circ} \mathrm{C}(\mathrm{A})$ and $30^{\circ} \mathrm{C}(\mathrm{B})$

Due to the increase of quercetin in solution the next step of investigation was to establish the antioxidant properties of those aqueous systems. It was found (Figure 4) the scavenging ability increase when cyclodextrin concentration increases as well. The phenomenon is easy to explain as a result of enhanced complexation of guest (quercetin) in the case when more host molecules are in the system. On the other hand the temperature dependencies are not clear in this case. The highest scavenging activity was observed at lowest and highest temperature. Intermediate temperatures of the complexation result in lower antioxidant activity of obtained systems. Those findings are difficult to explain by means of simple concentration/temperature phenomena. The hypothesis in this case may be set that the process of complexation is dominant at lowest temperature due to thermodynamics of the process. On the other hand the simple increase of 
quercetin solubility in water with temperature may be the result of higher concentration of antioxidant in this case.

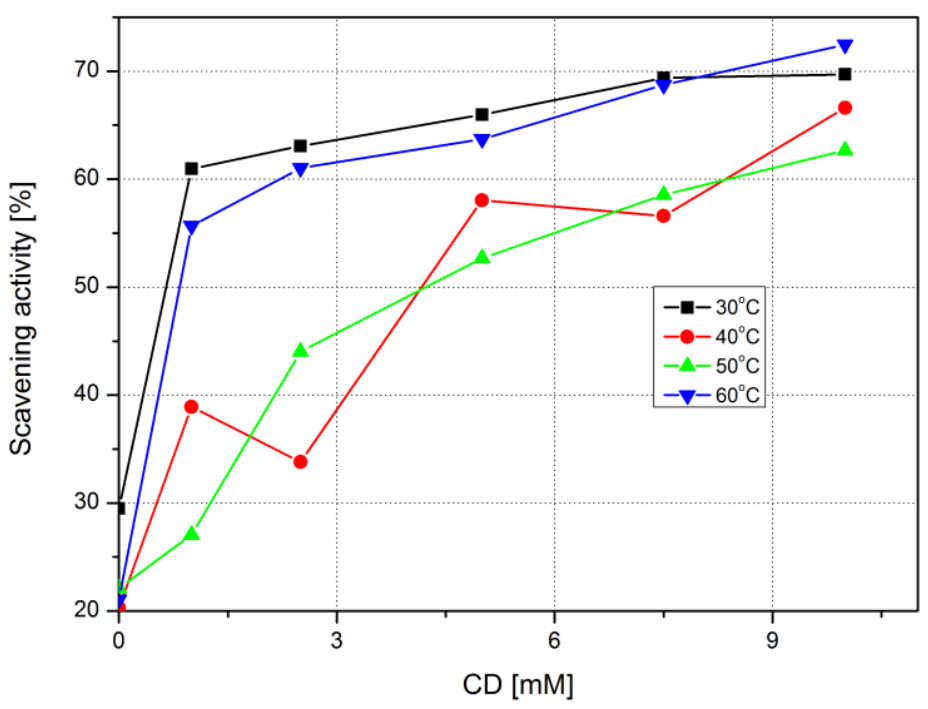

Figure 4. Free radical scavenging activity of QC aqueous solutions

In order to clarify the problem some thermodynamics calculation should be done. According to that the stability constant for quercetin/cyclodextrin complex $-\mathrm{K}_{\mathrm{F}}$ as well as standard enthalpy and entropy of complexation has been estimated. Additionally Gibbs free energy has been evaluated as well. The results obtained based on Higuchi-Connors method for $\mathrm{K}_{\mathrm{F}}$ calculation . Thermodynamic parameters have been evaluated according to dell Valle ${ }^{8}$. Results of the study were presented in Table 1.

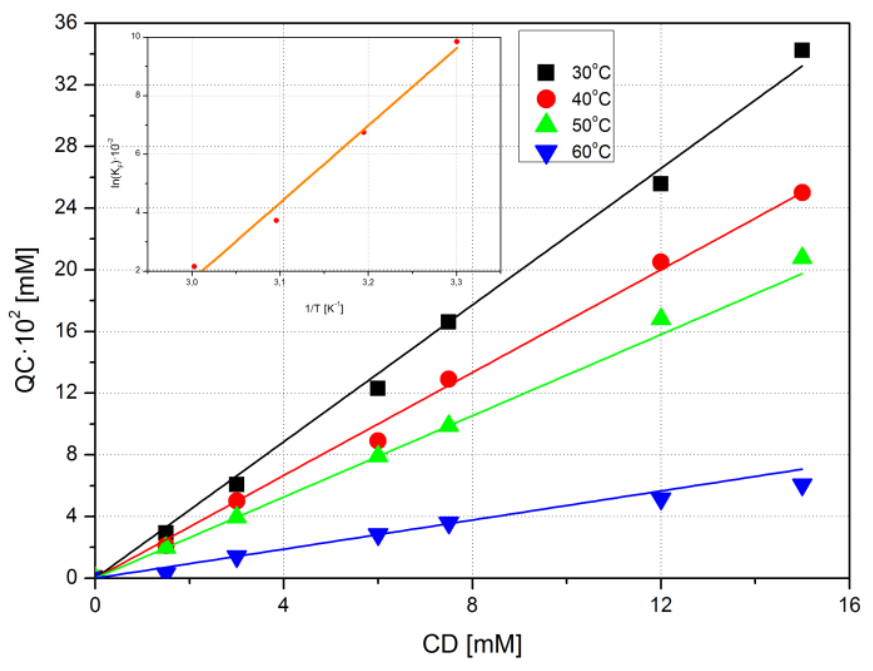

Figure 5. Solubility plot for $\mathrm{QC}$ in aqueous $\mathrm{CD}$ solutions 
On the basis of the calculation one can note that the complexation constant $K_{F}$ decreases with temperature by about one and a half order of magnitude. This may mean reducing the effects of a host - guest interaction with temperature. As a consequence hydrophobic interactions are strengthened at the cost of hydrogen bonding.

Table 1. Thermodynamics of quercetin complexation

\begin{tabular}{|c|c|c|c|c|}
\hline \multirow{2}{*}{$\begin{array}{c}\text { Temperature } \\
{\left[{ }^{\circ} \mathrm{C}\right]}\end{array}$} & \multirow{2}{*}{$\begin{array}{l}\mathrm{K}_{\mathrm{F}} \\
{\left[\mathrm{M}^{-1}\right]}\end{array}$} & $\Delta G^{O}$ & $\Delta \mathrm{H}^{\mathrm{O}}$ & $\Delta \mathrm{S}^{\mathrm{O}}$ \\
\hline & & \multicolumn{2}{|c|}{$\left[\mathrm{kJ} \cdot \mathrm{mol}^{-1}\right]$} & $\left.\Pi \cdot(\mathrm{mol} \cdot \mathrm{K})^{-1}\right]$ \\
\hline 30 & 980 & \multirow{4}{*}{$-17,05$} & \multirow{4}{*}{$-43,11$} & \multirow{4}{*}{80,35} \\
\hline 40 & 678 & & & \\
\hline 50 & 365 & & & \\
\hline 60 & 207 & & & \\
\hline
\end{tabular}

The obtained results allow to conclude that the complexation of quercetin on the CD is an exothermic process $\left(\Delta \mathrm{H}^{0}<0\right)$. The values of enthalpy changes indicate that during complexation some energy is releasing. This behavior is typical of hydrophobic interactions in the interior of the molecule where the $\mathrm{CD}$ is exchanged polar water molecules by the nonpolar guest molecules. The entropy changes for the complex formation process is rather low, but the value of this change is positive, similar to that observed in many other systems containing cyclodextrin ${ }^{8} . \Delta \mathrm{S}^{0}$ values close to zero may indicate the formation of a complex in which all the guest molecules are placed into the host'. This interpretation supports the hypothesis of complete coverage of the particles by the host molecule.

As the last stage of experiments an application of standard solubility models for complexation process is proposed. Two models were chosen as follows: modified Apelblat (1) model and Buchowski model $(2)^{10,11}$.

$$
\begin{gathered}
\ln \left(x_{m o l}\right)=A+\frac{B}{T}+C \cdot \ln (T)(\mathbf{1}) \\
\ln \left(1+\frac{\lambda \cdot\left(1-\mathrm{x}_{\mathrm{mol}}\right)}{x_{\mathrm{mol}}}\right)=\lambda \cdot \mathrm{H} \cdot\left(\frac{1}{\mathrm{~T}}-\frac{1}{\mathrm{~T}_{\mathrm{m}}}\right)
\end{gathered}
$$

In model (1) there are three constant A to C. The constants A and B may be explained as the variation in the solution activity coefficient and provide an information on the influence of nonideal solution on the solubility of solute. $\mathrm{C}$ parameter shows the effect of temperature on the enthalpy of fusion. On the other hand in (2) there are only two parameters. Those parameters reflect the nonideality of the solution system $(\lambda)$, and the enthalpy of the solution $(H)$. The $T_{m}$ parameter is the exact melting point of the solute. 
As one can see from Table 2 and 3 both models may be useful for describing the increase in quercetin solubility in the presence of cyclodextrin however the applicability of both models changes depending on $\mathrm{CD}$ concentration. Apelblat model gives more precise results in case of diluted CD solution while Buchowski-Ksiazczak in more concentrated ones.

Table 2. Apelblat model parameters

\begin{tabular}{|c|c|c|c|}
\hline & A & B & C \\
\hline 15,0 & 775,1 & $-40,43$ & $-114,8$ \\
\hline 12,0 & 595,0 & $-32,12$ & $-88,1$ \\
\hline 7,5 & 588,6 & -31.64 & $-87,3$ \\
\hline 5,0 & 633,2 & $-6,58$ & $-9,81$ \\
\hline 0,0 & $-16,2$ & $-2,06$ & 1,3 \\
\hline
\end{tabular}

Table 3. Buchowski-Ksiazczak model parameters

\begin{tabular}{|c|c|c|}
\hline & $\lambda \cdot 10^{6}$ & $H$ \\
\hline 15,0 & $-0,330$ & 63,07 \\
\hline 12,0 & $-0,331$ & 63,63 \\
\hline 7,5 & $-0,332$ & 57,03 \\
\hline 5,0 & $-0,334$ & 49,14 \\
\hline 0,0 & $-0,339$ & 29,61 \\
\hline
\end{tabular}

\section{Conclusion:}

A solubility and antioxidant activity study on ternary system quercetin/CD/water has been carried out. According to obtained results it may be stated that CD presented in the solution enhance the quercetin solubility by means of host-guest complexation. The obtained data suggest 1:1 complex to be formed and the process is spontaneous $\left(\Delta \mathrm{G}^{\mathrm{O}}<0\right)$. The modified Apelblat and Buchowski-Ksiazczak solubility models works well for the investigated system however their correlation to experimental data depends on $\mathrm{CD}$ concentration. The obtained solutions posses some antioxidant activity. Independently on quantitative results the complexation of quercetin by $\beta$-cyclodextrin has been proved. It opens new possibilities to apply the nonpolar insoluble flavonols also in water solutions.

\section{References:}

1. Brahmachari, G. \& Gorai, D. Progress in the research on naturally occurring flavones and flavonols: An overview. Curr. Org. Chem. 10, 873-898 (2006). 
2. Erlund, I. Review of the flavonoids quercetin, hesperetin, and naringenin. Dietary sources, bioactivities, bioavailability, and epidemiology. Nutr. Res. 24, 851-874 (2004).

3. Buttress, J., Saltmarsh, M., British Nutrition Foundation, Royal Society of Chemistry (Great Britain) \& Food Chemistry Group. Functional foods. (2000).

4. Bouktaib, M., Atmani, A. \& Rolando, C. Regio- and stereoselective synthesis of the major metabolite of quercetin, quercetin-3-O- $\beta-\mathrm{D}$-glucuronide. Tetrabedron Lett. 43, 6263-6266 (2002).

5. Murota, K. \& Terao, J. Antioxidative flavonoid quercetin: Implication of its intestinal absorption and metabolism. Arch. Biochem. Biophys. 417, 12-17 (2003).

6. Murota, K. Efficiency of Absorption and Metabolic Conversion of Quercetin and Its Glucosides in Human Intestinal Cell Line Caco-2. Arch. Biochem. Biophys. 384, 391-397 (2000).

7. Higuchi, T. \& Connors, K.A. in Adv. Anal. Chem. Instrum. 117-212 (1965).

8. Del Valle, E. M. M. Cyclodextrins and their uses: a review. Process Biochem. 39, 1033-1046 (2004).

9. Loftsson, T., Ólafsdóttir, B. J., Friðriksdóttir, H. \& Jónsdóttir, S. Cyclodextrin complexation of NSAIDSs: physicochemical characteristics. Eur. J. Pharm. Sci. 1, 95-101 (1993).

10. Buchowski, H., Ksiazczak, A. \& Pietrzyk, S. Solvent activity along a saturation line and solubility of hydrogen-bonding solids. J. Phys. Chem. 84, 975-979 (1980).

11. Apelblat, A. \& Manzurola, E. Solubilities of o-acetylsalicylic, 4-aminosalicylic, 3,5dinitrosalicylic, and p-toluic acid, and magnesium-DL-aspartate in water from $\mathrm{T}=(278$ to 348) K. J. Chem. Thermodyn. 31, 85-91 (1999).

\section{Acknowledgment:}

The Polish State Committee supported the research for Scientific Research Grant

No. N312 331240 